\title{
Pemulihan Pascabencana pada Anak Usia Dini dalam Perspektif Teori Ekologi
}

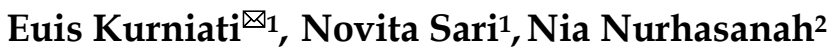 \\ Pendidikan Anak Usia Dini, Universitas Pendidikan Indonesia(1) \\ Teknologi Pendidikan, Universitas Negeri Surabaya Indonesia(2) \\ DOI: $10.31004 /$ obsesi.v6i1.1026
}

\begin{abstract}
Abstrak
Pemulihan pascabencana merupakan normalisasi kehidupan masyarakat yang terdampak bencana. Pada anak usia dini, kajian lebih difokuskan pada penanganan mengurangi trauma dengan berbagai pendekatan, sementara artikel ini menelaah pemulihan pascabencana dengan sudut pandang teori ekologi. Artikel ini ditulis dengan menggunakan kajian pustaka pada sumber yang terkait dengan pemulihan pasca bencana, teori ekologi dan anak usia dini. Hasil analisis menunjukkan bahwa pemulihan pascabencana pada anak usia dini akan dipengaruhi oleh konteks lingkungan disekitar anak seperti keluarga, teman dan masyarakat termasuk situasi bencana yang dihadapi oleh anak sebagai transisi ekologi (ecological transition). Pemulihan pascabencana dalam sudut pandang teori ekologi menekankan pentingnya proses interaksi anak usia dini dengan lingkungan mikrosistem, ekosistem dan makrosistem. Anak usia dini yang menjalani proses pemulihan pascabencana perlu didorong untuk berinteraksi dengan lingkungan sekitarnya dengan memperhatikan empat unsur interaksi yaitu processes, person, context dan time.
\end{abstract}

Kata Kunci: pemulihan; pascabencana; anak usia dini; teori ekologi.

\begin{abstract}
Post-disaster recovery is a normalization of the lives of people affected by disasters. In early childhood, studies are more focused on managing trauma reduction with various approaches, while this article examines post-disaster recovery from the perspective of ecological theory. This article was written using a literature review on sources related to post-disaster recovery, ecological theory, and early childhood. The results of the analysis show that post-disaster recovery in early childhood will be influenced by the environmental context around the child such as family, friends, and society, including the disaster situations faced by children as an ecological transition. Post-disaster recovery from the ecological theory view emphasizes the importance of the interaction process of early childhood with the microsystem, ecosystem, and macrosystem environment. Early childhood who undergo the post-disaster recovery process needs to be encouraged to interact with the surrounding environment by paying attention to the four elements of interaction, namely processes, person, context, and time.
\end{abstract}

Keywords: recovery; post-disaster; early childhood; ecological theory.

Copyright (c) 2021 Euis Kurniati, Novita Sari, Nia Nurhasanah

$\triangle$ Corresponding author:

Email Address : euiskurniati@upi.edu (Bandung, Jawa Barat, Indonesia)

Received 5 January 2021, Accepted 3 Juni 2021, Published 16 June 2021 


\section{PENDAHULUAN}

Kondisi geografis Indonesia termasuk ke dalam wilayah yang rawan bencana alam. Di Indonesia terdapat Ring of Fire on Pacific Rims atau biasa disebut dengan wilayah Cincin Api Pasifik, hal tersebut kerap mengakibatkan terjadinya gempa bumi, longsor, letusan gunung berapi, dan tsunami. Ring of Fire on Pacific Rims merupakan rumah bagi gunung api aktif yang ada di dunia dan sekitar $90 \%$ tempat terjadinya gempa bumi. Sekitar $13 \%$ dari jumlah gunung api di dunia berada di Indonesia diantaranya adalah 500 gunung berapi yang berstatus tidak aktif, dan 129 gunung berapi yang berstatus aktif, memiliki potensi letusan yang cukup besar mencapai $60 \%$ dari jumlah gunung api tersebar, selain itu memiliki bentuk daerah yang seperti tapal kuda dan dapat mencakup wilayah sepanjang $40.000 \mathrm{~km}$ (Gosal et al., 2018).

Sejak tahun 2000, di Indonesia tercatat banyak terjadi bencana alam di antaranya adalah pada tahun 2004 gempa bumi dan tsunami di Aceh, tahun 2006 terjadi gempa bumi di Bantul dan Yogyakarta, terjadi tsunami pada tahun 2006 di Pangandaran, tahun 2009 gempa bumi di Padang, tahun 2010 di Jawa Tengan telah terjadi letusan gunung api, pada tahun 2018 gempa bumi dan tsunami yang melanda Palu dan Donggala serta tsunami di Selat Sunda akibat dari letusan gunung anak Krakatau pada tahun 2018, serta banjir bandang dan lonsor di Papua pada tahun 2019 (Wikipedia Ensiklopedia bebas, 2020). Bencana ini telah memberikan dampak traumatis pada korban termasuk anak usia dini, Kousky, (2016) menyatakan bahwa kemungkinan setengah dari korban bencana adalah anak-anak.

Pada anak usia dini, bencana memberikan dampak fisik, psikologis dan sosial. Tidak sedikit anak yang menjadi korban jiwa, korban luka-luka, dan kehilangan tempat tinggalnya (Kurniati et al., 2020). Secara umum, bencana alam juga dapat berdampak pada kerusakan dan kerugian pada mata pencaharian, infrastruktur, properti serta sumber daya lingkungan sebagaimana dipaparkan Istriyani (2018) bahwa bencana alam berdampak terhadap sumber daya alam atau aset produktif yang nantinya akan mempengaruhi aspek sosial ekonomi masyarakat. Belum lagi munculnya permasalahan psikologis yang seringkali terabaikan pascabencana, sebab pada dasarnya permasalahan psikologis muncul tidak lama setelah bencana tiba, dan terjadi dalam jangka waktu yang cukup lama (Kaplow, J. B., Saxe, G. N., Putnam, F. W., Pynoos, R. S., \& Lieberman, 2006; Baggerly \& Exum, 2007; Kulkarni, M., Pole, N., \& Timko, 2013)

Dampak bencana yang dipaparkan di atas tidak sedikit yang berakhir pada situasi traumatis, sementara itu trauma pada anak usia dini sering kali terulang kembali pada masa remaja. Hal ini menunjukkan perlunya program pemulihan pascabencana yang terencana, sebelum dampak bencana terjadi dan setelah dampak bencana terjadi (Costello et al., 2003; Lindell, 2013). Dalam program pemulihan pascabencana, kemungkinan mekanismenya mengarah pada PTSD (Post Traumatic Stress Disorder), termasuk keterampilan koping dan proses pemulihan trauma (Salloum \& Overstreet, 2012).

Pendampingan untuk pemulihan trauma yang dialami oleh korban merupakan pendampingan yang terstruktur dengan menggunakan metode terapi psikologis, tujuannya adalah agar dapat berfungsi kembali secara normal. Kegiatan pemulihan sosial psikologis yang dapat dilakukan diantaranya adalah konseling baik dilakukan secara individu ataupun secara kelompok, melakukan pelatihan, kegiatan psikososial dan kegiatan psikoedukasi. Pendekatan eklektif dapat digunakan dalam proses pemulihan pascabencana seperti model Sequentially Planned Integrative Counseling for Children (SPICC), model ini telah banyak memperoleh dukungan dari riset-riset terdahulu (Geldard et al., 2017; Latipun, 2014). Terdapat 5 fase yang dapat dilaksanakan dari model ini yaitu:

Fase 1: membangun hubungan dengan anak agar anak bersedia menceritakan tentang dirinya, anak hendaknya merasakan aman dan nyaman dan pendekatan yang digunakan pada tahap ini adalah client center therapy.

Fase 2: melakukan penelaahan pengalaman anak-anak secara internal dan eksternal sehingga anak menyadari tentang keadaan dirinya, mau menerima diri dan bertanggungjawab dengan pilihannya, pada tahap ini pendekatan yang digunakan adalah terapi gestalt. 
DOI: $10.31004 /$ obsesi.v6i2.1026

Fase 3: pendekatan yang digunakan pada tahap ini adalah terapi naratif, anak akan mulai mengembangkan sudut pandang yang berbeda tentang dirinya sehingga terbangun kepercayaan diri, teknik yang digunakan bisa dengan bermain pasir, playdough, boneka, dll.

Fase 4: tujuan pada tahap ini adalah agar anak dapat mengarahkan diri dengan mengubah pola pikirnya, hal ini agar anak mampu mempertahankan perilaku positif yang telah diubahnya. Pendekatan yang digunakan pada tahap ini adalah terapi cognitive behavioral.

Fase 5: pendekatan yang digunakan pada tahap ini adalah terapi behavioral yang bertujuan agar anak terus berlatih, mencoba, serta mengevaluasi sehingga dapat beradaptasi dengan situasi yang baru.

Paparan di atas menjelaskan pemulihan pascabencana pada individu termasuk anak usia dini lebih ditekankan pada pendekatan penanganan dalam mengurangi trauma pada korban (Davis \& Parr, 2001), namun penelaahan pemulihan pascabencana dengan sudut interaksi anak dengan lingkungannya seperti yang dibahas teori ekologi belum banyak dilakukan. Teori ekologi melihat bahwa perkembangan anak terjadi melalui sistem lingkungan yakni terdiri dari tiga sistem diantaranya mikrosistem, eksosistem, dan makrosistem (Bronfenbrenner, 1979; Bronfenbrenner \& Morris, 1998; Shalih, 2019). Mikrosistem terdiri dari lingkungan tempat tinggal, teman sebaya, keluarga, dan sekolah, dimana semua itu dapat mempengaruhi perkembangan anak, maka dari itu mikrosistem merupakan lingkungan tempat tinggal seseorang dapat mempengaruhi perkembangan individu tersebut (Bronfrenbrenner, 1976; Mujahidah, 2015). Eksosistem merupakan sistem sosial dimana interaksi anak tidak terlibat secara langsung, meskipun begitu tetap berpengaruh terhadap perkembangan anak. Makrosistem terdiri dari agama, budaya, pemerintah, tradisi, ideologi negara, hukum, dan adat istiadat yang merupakan lapisan terluar dari lingkungan anak (Bronfenbrenner, 1979; Bronfenbrenner \& Morris, 1998; Shalih, 2019). Pemahaman pemulihan pascabencana dalam sudut pandang ini menjadi hal yang penting untuk dikaji mengingat akan memberikan pemahaman mengenai pentingnya pemetaan peran lingkungan dalam pemulihan pascabencana khususnya pada anak usia dini.

\section{METODOLOGI}

Metode yang digunakan dalam penelitian ini adalah studi literatur, yaitu penelaahan kritis terhadap informasi, gagasan, konsep, atau temuan yang telah ada di literatur tertentu untuk kemudian dirumuskan kembali menjadi konsep baru sesuai dengan topik yang diangkat. Pada studi literatur penelaahan tidak hanya sebagai persiapan namun juga merupakan kegiatan yang berkaitan dengan metode pengumpulan data pustaka, membaca, mencatat, mengumpulkan, mengolah dan menganlisis data penelitian (Zed, 2014). Literatur yang digunakan dalam penelitian ini adalah jurnal, buku, dokumen, dan kajian karya tulis yang telah tersedia. Metode ini dipilih dengan asumsi bahwa data penelitian yang dibutuhkan telah tersedia di berbagai sumber pustaka serta pisau analisis yang digunakan dalam bentuk kosep/teori. Dalam hal ini, peneliti melakukan penelaahan terhadap sumber data primer sebanyak 3 karya tulis ilmiah, dan didukung sumber data sekunder sebanyak 27 referensi karya tulis ilmiah yang terkait dengan pemulihan pascabencana, teori ekologi dan anak usia dini. Pustaka yang terkumpul dipetakan menjadi beberapa tema dan dianalisis dari sudut pandang teori ekologi Dengan mengacu pada literatur yang telah diperoleh, peneliti kemudian mengkaji realitas teoritis, menetapkan masalah, melakukan penggalian data, dilanjutkan dengan melakukan analisis dari data primer dan skunder dan terakhir diambil kesimpulan mengenai pemulihan pascabencana dalam perspektif teori ekologi. Desain penelitian diilistrasikan pada gambar 1. 


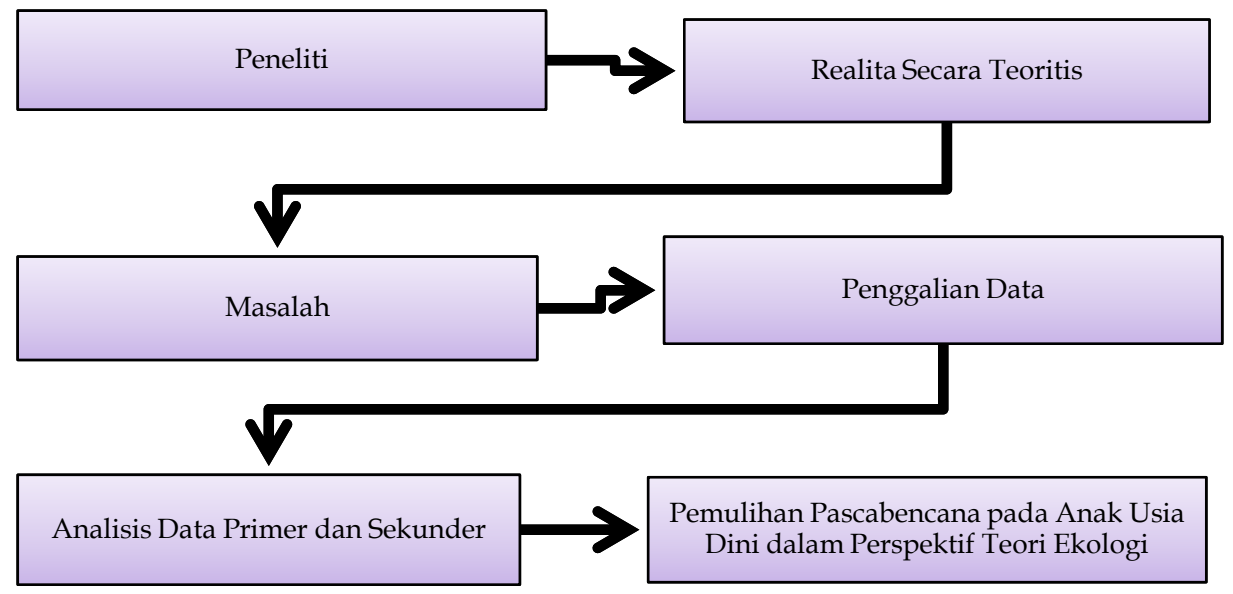

Gambar 1. Desain Penelitian

\section{PEMBAHASAN}

\section{Pemulihan Pascabencana dalam Tataran Mikrosistem dan Ekosistem}

Pemulihan pascabencana merupakan salah satu fase dari tiga manajemen bencana yang sangat penting yang meliputi; (1) Mitigasi, yakni melakukan persiapan terhadap penanganan untuk dapat mengurangi dampak yang ditimbulkan oleh bencana (2) Respons, yaitu sigap dalam mengambil tindakan setelah kejadian tujuannya adalah untuk meminimalisir korban jiwa dan kerusakan fisik dan properti; dan (3) pemulihan, yaitu proses normalisasi atau mengembalikan kepada keadaan normal (Beach, 2010).

Pemulihan pascabencana pada anak usia dini terfokus pada pemulihan kondisi fisik, psikologis dan sosial yang dilakukan melalui tahap edukasi dan konseptualisasi, pencapaian dan konsolidasi, serta keterampilan relaksasi dalam upaya mengatasi masalah psikologis dapat meliputi bantuan pendampingan, pelatihan, konseling, dan kegiatan psikososial (Wahyuni, 2017; Adiyoso, 2018), hal ini dilakukan karena akibat bencana anak-anak mengalami luka fisik, mereka pun tidak dapat melakukan kegiatan rutinitas harian, kehilangan anggota keluarga dan teman, kehancuran secara emosional, serta tidak memiliki rasa aman (Cupples, 2007; Jordan et al., 2013). Penanganan terhadap pengalaman traumatis akibat bencana diarahkan pada pemahaman dan upaya mengatasi kompleksitas risiko dari ketahanan dalam bencana yang melanda, yang mana bencana tersebut dapat menimbulkan kerugian harta benda bahkan mengancam keberlangsungan kehidupan, dan kondisi trauma masal pascabencana membutuhkan metode kolaborasi dan integrasi pengetahuan dari berbagai sistem dan tingkatan (Masten \& Narayan, 2012; Hastuti, 2016).

Pada proses pemulihannya, upaya yang diberikan lebih berorientasi pada konseling krisis disertai dengan dukungan sosial dari teman, saudara, keluarga, tetangga, dan juga sukarelawan Lindell, (2013), hal ini sejalan dengan pandangan teori ekologi yang menekankan pada pentingnya interaksi positif atau hubungan timbal balik antara anak dengan individu lain serta dengan lingkungan tempat tinggalnya. Teori ini menekankan tentang pentingnya interaksi yang dinamis dan kompleks antara individu dengan lingkungannya (Mujahidah, 2015). Anak usia dini yang menjadi korban bencana perlu didorong untuk mengadaptasi perubahan situasi dan kondisi yang dialami sebagai sebuah transisi ekologi (ecological transition). Transisi ekologi ini terjadi sebagai akibat dari perubahan peran, tatanan, atau keduanya, setiap transisi ekologis merupakan konsekuensi sekaligus pemicu proses perkembangan (Bronfenbrenner, 1979)

Pemulihan pascabencana pada konteks mikrosistem juga menekankan pentingnya proses interaksi antara anak usia dini dengan lingkungan belajar seperti ruangan, fasilitas bermain dan lingkungan menjadi suatu hal yang sangat sentral terkait dalam pencapaian perkembangan dan belajarnya (Hayes et al., 2017). Dalam kaitannya dengan pemulihan pasca bencana peran ayah, ibu, kakak, adik, teman dan guru menjadi sangat penting dalam 
membangun hubungan yang suportif dan positif dalam membantu proses pemulihan pascabencana. Hubungan seperti ini akan membantu mempercepat pemulihan dampak psikologis, fisik dan juga sosial anak usia dini. Anak perlu didorong secara aktif ikut terlibat, berperan dan berinteraksi dalam membangun pemulihan bersama pascabencana.

Pada konteks lingkungan ekosistem, pemulihan pascabencana ini dapat berupa pemanfaatan media baik secara umum maupun media pembelajaran yang diarahkan untuk membangun kesiapsiagaan dan resiliensi dalam menghadapi bencana. Media yang berperan secara aktif memberikan edukasi terhadap anak usia dini dan masyarakat secara luas dapat menjadi sarana dalam meningkatkan pemahaman mengenai kebencanaan sekaligus sebagai media dalam pemulihan pascabencana itu sendiri. Lingkungan lain yang termasuk pada konteks ini di antaranya adalah lingkungan kerja orang tua, lingkungan pergaulan, lingkungan keluarga besar dari ibu atau bapak, peraturan sekolah, media cetak atau visual seperti TV, dan koran berperan penting dalam membangun interaksi yang positif antara anak dengan ekosistemnya. Anak belajar di dalam konteks, lingkungan, tempat dan orang-orang yang memberikan pengaruh dalam perkembangannya (Hayes et al., 2017).

\section{Konsep Makrosistem dalam Rehabilitasi dan Rekonstruksi Pascabencana}

Rehabilitasi merupakan perbaikan serta pemulihan pada aspek pelayanan publik di wilayah pascabencana (Adiyoso, 2018). Hal penting yang perlu diingat dalam proses rehabilitasi dan rekonstruksi pascabencana adalah kearifan lokal (local wisdom) sebagai bentuk dukungan sosial serta partisipasi aktif dari semua pemangku kepentingan (Shalih, 2019).

Peraturan Kepala Badan Nasional Penanggulangan Bencana Nomor 11 Tahun 2008 Tentang Pedoman Rehabilitasi Dan Rekonstruksi Pasca Bencana tahun 2008, menjelaskan bahwa rekonstruksi merupakan kembali melakukan pembangunan untuk sarana dan prasarana yang rusak di wilayah yang terdampak bencana. Rekonstruksi tersebut tujuannya adalah untuk memulihkan kembali sarana dan prasarana, kondisi mental dan fisik masyarakat, serta sosial ekonomi masyarakat (Adiyoso, 2018). Rekonstruksi merupakan pemulihan kembali seluruh sarana dan prasarana, sosial budaya, perekonomian masyarakat, membangkitkan kembali peran masyarakat dalam segala aspek kehidupan di wilayah pascabencana (BNPB (Badan Nasional Penanggulangan Bencana), 2008; Ramli, 2011).

Peraturan Kepala Badan Nasional Penanggulangan Bencana Nomor 11 Tahun 2008 Tentang Pedoman Rehabilitasi Dan Rekonstruksi Pascabencana, (2008) menjelaskan bahwa rehabilitasi merupakan perbaikan serta pemulihan pada semua aspek pelayanan publik pada wilayah yang terdampak dengan tujuan utama yaitu untuk normalisasi atau berjalan kembali secara normal pada semua aspek kehidupan masyarakat dan pemerintahan pada wilayah pascabencana. Rehabilitasi yang dilakukan di wilayah pascabencana tidak hanya perbaikan lingkungan daerah bencana, sarana dan prasarana umum dan perbaikan rumah masyarakat, akan tetapi pemulihan di bidang ekonomi, pemulihan psikologis, pemulihan budaya, pemulihan keamanan dan ketertiban, pemulihan fungsi pemerintah dan pelayanan publik, serta pelayanan kesehatan. Rehabilitasi merupakan memperbaiki seluruh aspek pelayanan masyarakat sampai memadai untuk wilayah pascabencana, sasaran utamanya adalah normalisasi semua aspek kehidupan masyarakat dan pemerintah di wilayah pascabencana (Ramli, 2011:38).

Pemulihan pascabencana akan efektif jika masyarakat ikut terlibat dalam proses perencanaan yang mengarah kepada keberfungsian pemulihan secara keseluruhan agar menjadi bagian dari mitigasi bencana serta terlibat aktif dalam pelaksanaannya (Lindell, 2013). Menurut Adiyoso, (2018) pengkajian akibat bencana, kebutuhan saat bencana, dan dampak bencana merupakan upaya untuk mencapai proses penyelenggaraan rehabilitasi dan rekonstruksi yang efektif dan efisien untuk memenuhi kebutuhan pascabencana. Berikut merupakan bagan proses pengkajian kebutuhan pascabencana merujuk pada Peraturan 
Kepala Badan Nasional Penanggulangan Bencana Nomor 15 Tahun 2011 Tentang Pedoman Pengkajian Kebutuhan Pasca Bencana, (2008):

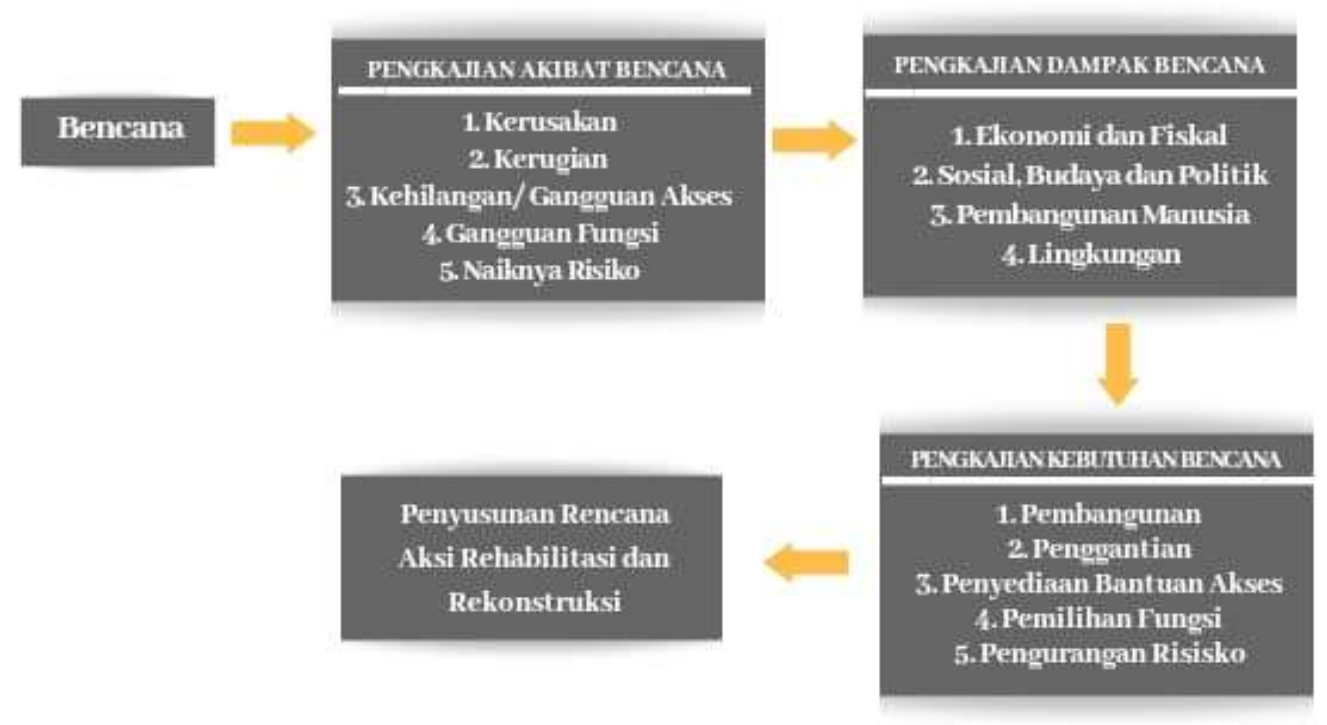

Gambar 2. Bagan proses pengkajian kebutuhan pascabencana

Rehabilitasi dan rekonstruksi pada konteks makrosistem direpresentasikan dalam bentuk lahirnya kebijakan pemerintah, peraturan pemerintah, kearifal lokal, keagamaan dalam memberikan dukungan, perlindungan dan pemulihan pascabencana. Pada konteks ini kebijakan rehabilitasi dan rekonstruksi baik sarana maupun prasarana menjadi sistem dengan lapisan terluar dari lingkungan anak sama halnya dengan ideologi negara, pemerintahan, adat istiadat, budaya dan tradisi, hukum dan agama.

Teori ekologi Bronfenbrenner menekankan pada perkembangan individu dan sistem interaksi yang lebih komplek, bahwa bukan hanya ada individu dan lingkungan namun proses interaksi yang terjadi di dalamnya. Proses ini merupakan bentuk interkasi antara organisme dan lingkungan. Proses ini memberikan pengaruh terhadap berbagai perkembangan yang berbasis pada karakteristik individu, konteks lingkungan baik yang terdekat dengan anak maupun yang luas serta situasi yang terjadi. Agar efektif maka hendaknya dibangun interaksi yang berkualitas, yang membangun hubungan dan menjalin komunikasi yang positif dan dilakukan secara imbang sepanjang waktu.

Bronfenbrenner menjelaskan konsep PPCT sebagai 4 unsur penting dalam berinteraksi yaitu; 1) Proses (Processes) yaitu konsep proses proksimal di dalam perkembangan manusia, yang merupakan mesin perkembangan, sehingga anak bisa merasa terikat (enggaged) dalam berinteraksi dengan lingkungan di sekitarnya seperti interaksi saat mengasuh, bermain dengan adik kecil atau dengan teman sebaya, membaca, dll. Peran orang dewasa disekitar anak adalah menghargai, mendukung, dan memperluas belajar anak, karena segala bentuk pendidikan, upaya, konten, dan arahan dalam melakukan proksimal proses akan berdampak secara sistematis pada perkembangan anak. 2) Individu (Person) perkembangan individu ditentukan juga oleh karakteristik individu itu sendiri dalam berinteraksi dengan lingkungannya, anak secara aktif berperan dalam konteks lingkungannya. Anak yang memiliki kepercayaan diri dan memiliki kemampuan berkomunikasi dengan baik mampu memotivasi anak lainnya untuk berinteraksi baik dengan objek maupun lingkungannya sehingga penting untuk membangun interaksi yang positif pada anak usia dini. 3) Konteks lingkungan(Context) baik lingkungan yang langsung bersentuhan dengan anak seperti keluarga, sekolah, tetangga atau lingkungan yang lebih luas seperti budaya, keyakinan, nilai, dan kebijakan politik. 4) Waktu (Time) Bronfenbrenner mengidentifikasi tiga waktu yang dapat berdampak pada proses proksimal dalam perkembangan anak-anak, yaitu; 1) 'waktu mikro' merujuk pada apa yang terjadi selama interaksi atau aktivitas tertentu; 2) 'Mesotime' 
merujuk pada sejauh mana dan seberapa konsisten aktivitas dan interaksi yang terjadi antara anak dengan lingkungan; dan 'macrotime' merujuk pada konteks historis perkembangan anak dan waktu kejadian tertentu dalam kehidupan anak (Greene et al., 2014; Hayes et al., 2017).

Paparan di atas menunjukkan bahwa penanganan pemulihan pascabencana selain perlu dilakukan secara lokal, regional, nasional, dan internasional (Bowman \& Roysircar, 2011; Goldsmith, 2014) tetapi perlu ditangani secara personal dan interaksional yang tidak melepaskan proses interaksi antara anak dengan lingkungannya. Hal ini sejalan dengan teori ekologi Bronfenbrenner yang menekankan pada lingkungan sebagai bagian yang tidak terpisahkan dari proses perkembangan individu (Shalih, 2019). Proses interaksi antara individu dan lingkungan akan membentuk tingkah laku yang sesuai dengan lingkungannya, sehingga menempatkan lingkungan sebagai hal yang sama pentingnya dan merupakan pendidik ketiga setelah orang tua dan guru. Melalui pemetaan yang seimbang dan sesuai dengan kebutuhan anak usia dini pada saat penanganan pemulihan pascabencana dengan melakukan interaksi dengan konteks mikrosistem, ekosistem dan makrosistem diharapkan dapat mempercepat proses pemulihan pascabencana yang dihadapi oleh anak usia dini.

\section{SIMPULAN}

Pemulihan pascabencana pada anak usia dini akan dipengaruhi oleh konteks lingkungan disekitar anak seperti keluarga, teman dan masyarakat termasuk situasi bencana yang dihadapi oleh anak sebagai transisi ekologi. Pemulihan pascabencana dalam sudut pandang teori ekologi menekankan pentingnya proses interaksi anak usia dini dengan lingkungan mikrosistem, ekosistem dan makrosistem. Anak usia dini yang menjalani proses pemulihan pascabencana perlu didorong untuk berinteraksi dengan lingkungan sekitarnya dengan memperhatikan empat unsur interaksi yaitu processes, person, context dan time.

\section{UCAPAN TERIMA KASIH}

Terima kasih disampaikan kepada Sekolah Pasacasarja Universitas Pendidikan Indonesia atas pemberian hibah penelitian bidang ilmu tahun anggaran 2020.

\section{DAFTAR PUSTAKA}

Baggerly, J., \& Exum, H. A. (2008). Counseling children after natural disasters: Guidance for family therapists. American Journal of Family Therapy, 36(1), 79-93. https:// doi.org/10.1080/01926180601057598

Beach, M. (2010). Disaster Preparednes and Mana- gement. F.A. Davis CompanY.

BNPB. (2012). Peraturan Kepala Badan Nasional Penanggulangan Bencana Nomor 15 Tahun 2012 Tentang Pedoman Pusat Pengendalian Operasi Penanggulangan Bencana (Pusdalops-PB). Badan Nasional Penanggulangan Bencana, 15(1), 1-43.

BNPB (Badan Nasional Penanggulangan Bencana). (2008). Perka BNPB Nomor 11 Tahun 2008 tentang Pedoman Rehabilitasi dan Rekonstruksi Pasca Bencana. Perka BNPB, 11(3), 463-466.

Bowman, S. L., \& Roysircar, G. (2011). Training and Practice in Trauma, Catastrophes, and Disaster Counseling. The Counseling Psychologist, 39(8), 1160-1181. https://doi.org/10.1177/0011000010397934

Bronfenbrenner, U. (1979). The Ecology of Human Development. Experiment by Nature and Design. Harvard University Press.

Bronfenbrenner, U., \& Morris, P. (2006). The ecology of developmental processes. In Handbook of child psychology. Theoretical models of human development (Vol. 01, Issue 9, pp. 793-828).

Costello, E. J., Compton, S. N., Keeler, G., \& Angold, A. (2003). Relationships between Poverty and Psychopathology: A Natural Experiment. Journal of the American Medical Association, 290(15), 2023-2029. https://doi.org/10.1001/jama.290.15.2023 
Cupples, J. (2007). Gender and Hurricane Mitch: Reconstructing subjectivities after disaster. Disasters., 13(2), 155-175. https:// doi.org/10.1111/j.1467-7717.2007.01002.x

Davis, M. J., \& Parr, M. J. (2001). Trauma systems. Current Opinion in Anaesthesiology, 14(2), 185-189. https://doi.org/10.1097/00001503-200104000-00010

Geldard, K., Geldard, D., \& Foo, R. Y. (2017). Counselling Children: A Practical Introduction (5th Edition). In SAGE Publications.

Goldsmith, R. E. (2014). Systemic Trauma. Journal of Trauma and Dissociation, 15(2), 117-132. https://doi.org/10.1080/15299732.2014.871666

Gosal, C., Tarore, R. C., \& Karongkong, H. H. (2018). Analisis Spasial Tingkat Kerentanan Bencana Gunung Api Lokon di Kota Tomohon. Jurnal Spasial, 5(2), 229-237.

Greene, S., Morgan, M., McCrory, C., \& McNally, S. (2014). Growing up in Ireland: National Longitudinal Study of Children. Office Of The Minister For Children And Youth Affairs. $\quad$ http://www.growingup.ie/fileadmin/user_upload/doc uments/1st_Report/Barcode_Growing_Up_in_Ireland_-_The_Lives_of_9-YearOlds_Main_Report.pdf

Hastuti. (2016). Peran Perempuan dalam Menghadapi Bencana di Indonesia. Geomedia: Majalah Ilmiah Dan Informasi Kegeografian, 14(2), 13-21. https:// doi.org/10.21831/gm.v14i2.13812

Hayes, N., O'Toole, L., \& Halpenny, A. M. (2017). Introducing bronfenbrenner, a guide for practitioners and sudents in early years education. Routledge. https://doi.org/10.4324/9781315646206

Istriyani, R. (2018). Kontribusi Pemuda dalam Menjawab Permasalahan Sosial Ekonomi $\begin{array}{lllll}\text { Pascabencana. Jurnal Studi } & \end{array}$ https:// doi.org/10.22146/studipemudaugm.36815

Jordan, B., Perryman, K., \& Anderson, L. (2013). A case for child-centered play therapy with natural disaster and catastrophic event survivors. International Journal of Play Therapy, 22(4), 219-230. https://doi.org/10.1037/a0034637

Kaplow, J. B., Saxe, G. N., Putnam, F. W., Pynoos, R. S., \& Lieberman, A. F. (2006). The longterm consequences of early childhood trauma: A case study and discussion. Psychiatry, 69(4), 362-375. https:/ / doi.org/10.1521/psyc.2006.69.4.362

Kousky, C. (2016). Impacts of natural disasters on children. Future of Children, 1(26), 73-92. https:// doi.org/10.1353/foc.2016.0004

Kulkarni, M., Pole, N., \& Timko, C. (2013). Childhood victimization, negative mood regulation, and adult PTSD severity. Psychological Trauma: Theory, Research, Practice, and Policy, 5(4), 359-365. https:// doi.org/10.1037/a0027746

Kurniati, E., Adriany, V., Mirawati, M., El-Seira, R. M., \& Winangsih, I. (2020). Identifikasi Kesiapsiagaan Guru PAUD sebagai Upaya Pengurangan Risiko Bencana Banjir di Bandung. Jurnal Obsesi: Jurnal Pendidikan Anak Usia Dini, 4(2), 840. https://doi.org/10.31004/obsesi.v4i2.388

Latipun. (2014). Pemulihan Trauma Berbasis Komunitas: Pengalaman Indonesia dalam Intervensi Trauma Massal. Jurnal Sains Dan Praktik Psikologi, 2(3), 278-285. https:// doi.org/10.22219/procedia.v3i1.2177

Lindell, M. K. (2013). Recovery and reconstruction after disaster. In Encyclopedia of Earth Sciences Series (pp. 812-824). https:// doi.org/10.1007/978-1-4020-4399-4_285

Masten, A. S., \& Narayan, A. J. (2012). Child development in the context of disaster, war, and terrorism: Pathways of risk and resilience. In Annual Review of Psychology (Vol. 63, Issue 1, pp. 227-257). https:/ / doi.org/10.1146/annurev-psych-120710-100356

Mujahidah. (2015). Impementasi Teori Ekologi Bronfrenbreneur dalam Membangun Pendidikan Karakter yang Berkualitas. Lentera, 2(IXX).

Ramli, S. (2011). Pedoman Praktis Manajemen Bencana. Dian Rakyat. 
DOI: $10.31004 /$ obsesi.v6i2.1026

Salloum, A., \& Overstreet, S. (2012). Grief and trauma intervention for children after disaster: Exploring coping skills versus trauma narration. Behaviour Research and Therapy, 50(3), 169-179. https:// doi.org/10.1016/j.brat.2012.01.001

Shalih, O. (2019). Evaluasi Pelaksanaan Rehabilitasi dan Rekonstruksi Pascabencana. Geospasial, 13(3), 12-14. https:// doi.org/10.31227/osf.io/9yg4e

Wahyuni, E. N. (2017). Mengelola Stres Dengan Pendekatan Cognitive Behavior Modification (Studi Eksperimen Pada Mahasiswa Baru Pendidikan Agama Islam (Pai) Fakultas Ilmu Tarbiyah \& Keguruan Uin Maliki Malang). Tadrib, 3(1), 99-117. https://doi.org/10.19109/Tadrib.v3i1.1385

Wikipedia Ensiklopedia bebas. (2020). Bencana alam di Indonesia sejak tahun 2004. 